Revised manuscript.

The final version was published in:

Reactive and functional polymers, 2018 133, 21-28

doi:10.1016/j.reactfunctpolym.2018.09.015 


\title{
Amino acid based polymer hydrogel with enzymatically degradable cross-links
}

Barnabás Áron Szilágyi ${ }^{\mathrm{a}}$ Árpád Némethy ${ }^{\mathrm{a}}$, Anna Magyar ${ }^{\mathrm{b}}$, Ildikó Szabób, Szilvia Bősze ${ }^{\mathrm{b}}$, Benjámin Gyarmati ${ }^{\mathrm{a}}$, András Szilágyi ${ }^{\mathrm{a}^{*}}$

aSoft Matters Group, Department of Physical Chemistry and Materials Science, Budapest University of Technology and Economics, Müegyetem rkp. 3, H-1111 Budapest, Hungary

${ }^{b}$ MTA-ELTE Research Group of Peptide Chemistry, Budapest 112, PO Box 32, H-1518

Budapest, Hungary

*corresponding author: András Szilágyi

E-mail: aszilagyi@mail.bme.hu, Phone: +36-1-463-3518, Fax: +36-1-463-3767

\begin{abstract}
The synthesis of a chemically cross-linked polymer hydrogel consisting exclusively of amino acids is described in this paper. A natural amino acid, aspartic acid was polymerized to polysuccinimide which was cross-linked by a tetrapeptide sequence designed for proteolytic degradation, and then the corresponding poly(aspartic acid) hydrogel was obtained by alkaline hydrolysis. The hydrogel dissolved in the presence of trypsin. According to in vitro cellular assays, the degradation products of the hydrogel cross-linked with the peptide were noncytotoxic and non-cytostatic. The sustained release of an encapsulated macromolecular model drug, FITC-dextran, was triggered by the degradation of the hydrogel induced by trypsin. These results suggest the potential application of the trypsin-responsive hydrogel for drug delivery in the small intestine.
\end{abstract}

Keywords: Hydrogel; Poly(aspartic acid); Enzymatic degradation; trypsin; Drug release 


\section{Introduction}

Polymer hydrogels are applied as biosensing materials [1], scaffolds for tissue engineering [2] or as drug delivery vehicles [3] owing to their large water uptake, biocompatibility and responsive properties. A wide variety of polymers, cross-linkers and cross-linking methods are in our hand to design hydrogels with tailor-made properties like hydrogels responsive to $\mathrm{pH}$, temperature, redox potential or other external stimuli [4-8]. Yet the most attractive stimulus for biomedical applications is the concentration gradient of biomolecules, like enzymes, in the human body. The most important advantages of using enzymes over other stimuli are their high selectivity, inherent biocompatibility and their availability at the site of action, i.e. they do not need to be added externally [9]. The possible responses to the presence of enzymes include swelling [10-13], gelation [14-18] or degradation. The degradation of polymer hydrogels can be classified into at least two different categories, such as the degradation of the polymer backbone $[19,20]$ or that of the cross-linkers [16,21-39]. The third possibility, cleavage of pendant groups from the backbone chains may or may not result in the dissolution of the hydrogel [40]. Various enzymes have been reported to induce such a response, e.g. dextranase [20], horseradish peroxidase $[14,17,18]$ or various proteases $[16,21-30,32-39]$. The hydrogels responsive to enzymes can be used as scaffolds with controlled rate of degradation [16,21$23,32,39]$ or in controlled drug delivery exploiting the change in the expression or activity of the enzymes at certain disease sites [27-29,35,36,41,42].

Hydrogels showing enzymatic response can be prepared by using peptide cross-linkers. The peptide sequence can be designed for selective cleavage by a protease enzyme available at the chosen therapeutic site. The presence of trypsin is a particularly attractive trigger for sitespecific drug delivery systems. Trypsin-degradable hydrogels have been already reported in the literature $[26,29,42]$, and they can be utilised for the protection of bioactive molecules (e.g. therapeutic proteins) in the stomach and for the release of them in the small intestine. Van Dijk and co-workers [26] reported the synthesis of a hydrogel by the use of the $\mathrm{Cu}(\mathrm{I})$-catalyzed 1,3dipolar cycloaddition of a trypsin-responsive bis-azido peptide and a star-shaped alkyne derivatized PEG. The degradation of the resulting hydrogel was induced by trypsin. Horava and co-workers [29] recently reported a $\mathrm{pH}^{-}$and enzyme-responsive microgel of poly(methacrylic acid)-g-poly(ethylene glycol) cross-linked with an oligopeptide composed of arginine (Arg, R), glycine (Gly, G) and lysine (Lys, K) for targeted cleavage by trypsin and resistance to degradation by pepsin. The hydrogel can be used for the oral administration of haematological factor IX for the treatment of haemophilia B. Enzymatically degradable 
hydrogels are often synthesized by the copolymerization of acrylated peptide derivatives [21,32-37]. Various click reactions are also used such as the Michael addition of cysteine thiols with vinyl-sulfone [16,22,39], maleimide [23] or norbornene functionalised poly(ethylene glycol) $[24,38]$. Copper catalyzed Huisgen cycloaddition of azido-terminated PEG and alkyneterminated peptides [25] or alkynated PEG and peptide azides [26] can be used as well. The carboxyl groups of the polymer and the terminal amine groups of the peptides can be coupled by p-nitrophenyl ester activation [27] or carbodiimide chemistry [28-30,42]. The drawback of all these methods is that they require the derivatization of the polymer before the cross-linking reaction, and the acrylate polymers are not biodegradable.

Apart from polymer hydrogels, enzyme-responsive physical gels have also been reported in the literature. Pochan and Schneider prepared a series of synthetic oligopeptides which are able to fold into $\beta$-hairpin, then self-assemble into a $\beta$-sheet rich network to form a self-supporting hydrogel [43]. The oligopeptides composed of 20 amino acids include a six residue sequence that is cleavable by matrix metalloproteinase-13, thus, these peptides have a potential as extracellular matrices for facilitating repair of damaged tissues [44].

In this work, a polymer hydrogel with trypsin-induced degradation was prepared exclusively from amino acids. The polymer backbone of the hydrogel is a pH-responsive poly(aspartic acid) (PASP) [5,6], a synthetic polymer, which is biocompatible [45] and biodegradable [46] due to its protein-like poly(amino acid) structure. PASP has a robust synthesis method allowing precise control over molecular structure [47,48]. The precursor anhydride of PASP, polysuccinimide (PSI), reacts with primary amines under mild reaction conditions. Thus, PSI can be cross-linked by any peptide bearing amine groups at both termini, which means that no activation of the peptide is required before cross-linking. In the present work, a tetrapeptide, composed of phenylalanine (Phe, F), arginine (Arg, R) and lysine (Lys, K), abbreviated as FRFK, was used as trypsin-degradable cross-linker. Degradation, biocompatibility, and drug release properties of the hydrogel were studied in comparison with a non-degradable poly(aspartic acid) hydrogel. 


\section{Experimental}

\subsection{Materials}

Imidazole $(99 \%)$, potassium chloride $(\mathrm{KCl})$, sodium chloride $(\mathrm{NaCl})$, dibasic sodium phosphate dihydrate $\left(\mathrm{Na}_{2} \mathrm{HPO}_{4} \cdot 2 \mathrm{H}_{2} \mathrm{O}\right)$, mesitylene $(99 \%)$, phosphoric acid $\left(85 \% \mathrm{H}_{3} \mathrm{PO}_{4}\right)$, methanol, dibutylamine (DBA, 99\%), and dithiothreitol (DTT, 99\%) were purchased from Reanal (Hungary). Monobasic potassium phosphate $\left(\mathrm{KH}_{2} \mathrm{PO}_{4}, 99.5 \%\right)$ L-aspartic acid (extra pure), sulpholane (99\%), cystamine dihydrochloride (CA, 98\%), and HPLC-grade acetonitrile $(\mathrm{MeCN})$ were bought from Merck. Hydrochloric acid (HCl), dimethyl sulfoxide (DMSO), dichloromethane (DCM), dimethylformamide (DMF), and diethylether were purchased from Molar Chemicals (Hungary). Deuterated dimethyl sulfoxide (DMSO-d 6 , 99.9 atom\% D, containing $0.03 \mathrm{v} / \mathrm{v} \%$ tetramethylsilane), trypsin (from porcine pancreas, Type IX-S, 1300020000 BAEE units/mg protein), and FITC-dextran $\left(M_{\mathrm{w}}=70 \mathrm{kDa}\right.$; FITC:glucose $\left.=1: 250\right)$ were bought from Sigma-Aldrich.

All amino acid derivatives (Fmoc-Phe-OH, Fmoc-Arg(Pbf)-OH, Fmoc-Lys(Boc)-OH), 2chlorotrityl-chloride resin, coupling reagents ( $N, N^{\prime}$-diisopropylcarbodiimide (DIC), 1hydroxybenzotriazole (HOBt)) and scavenger (triisopropylsilan (TIS)) were purchased from IRIS Biotech GmbH (Germany). Piperidine and trifluoroacetic acid (TFA) were Fluka products.

The imidazole buffer $(\mathrm{pH}=8 ; \mathrm{I}=0.15 \mathrm{M})$ was prepared by dissolving $6.81 \mathrm{~g}$ imidazole and $10.39 \mathrm{~g} \mathrm{KCl}$ in $1 \mathrm{dm}^{3}$ of water, the $\mathrm{pH}$ was adjusted with $1 \mathrm{M} \mathrm{HCl}$. The phosphate buffered saline (PBS) solution of $\mathrm{pH}=7.4$ was prepared by dissolving $8.00 \mathrm{~g}$ of $\mathrm{NaCl}, 0.20 \mathrm{~g}$ of $\mathrm{KCl}$, $1.44 \mathrm{~g}$ of $\mathrm{Na}_{2} \mathrm{HPO}_{4} \cdot 2 \mathrm{H}_{2} \mathrm{O}$ and $0.12 \mathrm{~g}$ of $\mathrm{KH}_{2} \mathrm{PO}_{4}$ in $1 \mathrm{dm}^{3}$ of water, the $\mathrm{pH}$ being adjusted with $0.1 \mathrm{M} \mathrm{HCl}$. The $\mathrm{pH}$ of the buffer solutions was checked with a Radelkis OP-271/1 pH/ion analyser.

For the in vitro cell culturing assays, RPMI-1640 medium, gentamicin, 3-(4,5dimethylthiazol-2-yl)-2,5-diphenyltetrazolium bromide (MTT) and fetal calf serum were obtained from Sigma-Aldrich. The 96-well microtest plates were the products of Sarstedt (Hungary).

All reagents were used without further purification and their quality was "for analysis" unless otherwise noted. Experiments were performed at room temperature $\left(\mathrm{T}=25^{\circ} \mathrm{C}\right)$ unless otherwise indicated. Ultrapure water $(\rho>18.2 \mathrm{M} \Omega \cdot \mathrm{cm}$, Millipore) was used for the preparation of aqueous solutions. 


\subsection{The synthesis of polysuccinimide}

Polysuccinimide (PSI) was synthesized by the thermal polycondensation of aspartic acid in a mixture of mesitylene and sulpholane ( $7 / 3$ weight ratio) at $160{ }^{\circ} \mathrm{C}$ with $85 \% \mathrm{H}_{3} \mathrm{PO}_{4}$ as catalyst (the molar ratio of $\mathrm{H}_{3} \mathrm{PO}_{4}$ to aspartic acid was $16 \%$ ). After $7 \mathrm{~h}$, the resultant polymer was filtered and dissolved in DMF, then precipitated with excess amount of water. The precipitate was washed with water and $\mathrm{MeOH}$ and dried at $80^{\circ} \mathrm{C}$. The chemical structure of PSI was confirmed by ${ }^{1} \mathrm{H}$ NMR (300 MHz, DMSO-d6, $\delta: 5.10(\mathrm{~d}, 1 \mathrm{H}, \mathrm{CH}) ; 3.20$ and $2.75\left(\mathrm{~s}, \mathrm{~s}, 2 \mathrm{H}, \mathrm{CH}_{2}\right)$ ). PSI was hydrolysed to poly(aspartic acid) (PASP) in a mildly alkaline solution (imidazole buffer, $\mathrm{pH}=8,24 \mathrm{~h}$ ), the solution was dialysed against water and the solid PASP was obtained by freeze-drying. The average molecular weight of the resultant PASP was determined by HPLC size-exclusion chromatography (SEC). A Nucleogel GFC-300 column was used (molecular weight range of 1-100 kDa) with PBS eluent. The average molecular weight of PASP was calculated to be $\mathrm{M}_{\mathrm{w}}=56.1 \mathrm{kDa}$ with a polydispersity index (PDI) of 1.07.

\subsection{Synthesis of the peptide cross-linker}

TFA salt of FRFK was synthesized by solid phase methodology using Fmoc-chemistry on 2-chlorotrityl-chloride resin [49] using diisopropylcarbodiimide/1-hydroxybenztriazole (DIC/HOBt) as coupling reagent. The protecting group of arginine and lysine were 2,2,4,6,7pentamethyldihydrobenzofuran-5-sulfonyl (Pbf) and tert-butyloxycarbonyl (Boc) groups, respectively. The tetrapeptide was cleaved off the resin in a solution containing $95 \%$ TFA, 2.5\% water and $2.5 \%$ triisopropylsilane by stirring the solution for $2 \mathrm{~h}$. The resin was removed by filtration, the filtrate was dropped into cold ether to precipitate the peptide. The ether was distilled three times to remove free TFA. The crude products were purified by semi-preparative reversed-phase high-performance liquid chromatography (RP-HPLC) and the purified compounds were characterized by analytical RP-HPLC (Fig. S1) and electrospray ionization ion trap mass spectrometry (ESI-IT-MS). The molecular mass of the FRFK tetrapeptide was 596.5 Da(Fig. S2).

\subsection{Synthesis of poly(aspartic acid) hydrogel cross-linked with the tetrapeptide}

The poly(aspartic acid) hydrogel cross-linked with the tetrapeptide (PASP-FRFK) was prepared by dissolving $14.6 \mathrm{mg}(150 \mu \mathrm{mol})$ PSI and $20.6 \mathrm{mg}(25 \mu \mathrm{mol})$ FRFK 2TFA in $106.7 \mathrm{mg}$ DMSO, then $8.1 \mathrm{mg}(62.5 \mu \mathrm{mol})$ dibutylamine (DBA) was added to initiate gelation, 
and the solution was vortexed. The gelation was carried out overnight, then the gel was placed into imidazole buffer $(\mathrm{pH}=8)$ to hydrolyse unreacted succinimide rings. The buffer was replaced daily for 3 days. PASP-FRFK was stored in PBS $(\mathrm{pH}=7.4)$ for further experiments. PASP-FRFK gel loaded with the model drug was prepared by dissolving PSI and FRFK in DMSO along with $2.91 \mathrm{mg}$ FITC-dextran $(20 \mathrm{w} / \mathrm{w} \%$ of the polymer) before the gelation. An oscillatory rheometer (Anton Paar Physica MCR 301, Austria) with plate-plate geometry (PP25, diameter $25 \mathrm{~mm}$, measuring gap $2.75 \mathrm{~mm}$, normal force $0.5 \mathrm{~N}$ ) was used to assess the mechanical properties of the hydrogel. Frequency sweep measurements were performed in the range of linear viscoelasticity with a strain of $1 \%$ in the angular frequency range of $\omega=1-100$ $\mathrm{rad} / \mathrm{s}$. The temperature was maintained at $25.0 \pm 0.1{ }^{\circ} \mathrm{C}$ using a Peltier system included in the rheometer. Three parallel samples were measured.

\subsection{Synthesis of poly(aspartic acid) hydrogel cross-linked with cystamine}

The poly(aspartic acid) hydrogel cross-linked with cystamine (PASP-CA) was prepared by dissolving $14.6 \mathrm{mg}$ PSI and $5.6 \mathrm{mg}$ cystamine dihydrochloride in $123.3 \mathrm{mg}$ DMSO, then 6.5 mg $(50 \mu \mathrm{mol})$ DBA was added, and the solution was vortexed. After gelation, the gel was hydrolysed in imidazole buffer $(\mathrm{pH}=8)$. The buffer was replaced daily for 3 days, then PASPCA was stored in PBS ( $\mathrm{pH}=7.4$ ) for further experiments. PASP-CA gel loaded with model drug was prepared similarly, but $2.91 \mathrm{mg}$ FITC-dextran was also dissolved in DMSO along with PSI and cystamine dihydrochloride before the cross-linking reaction.

\subsection{Enzymatic degradation of the PASP-FRFK hydrogel}

A gravimetric method was used to study the degradation of the PASP-FRFK hydrogels. Hydrogel pieces swollen in PBS were weighed (initial mass: $\sim 60 \mathrm{mg}$ ), then immersed in $5 \mathrm{ml}$ trypsin solution prepared in PBS $(\mathrm{c}=2 \mathrm{mg} / \mathrm{ml})$. Hydrogels were weighed at predetermined time intervals. Relative mass was defined as the percentage ratio of the mass of the hydrogels at a given time to the initial mass. PASP-FRFK in PBS without trypsin and PASP-CA in PBS containing $2 \mathrm{mg} / \mathrm{ml}$ trypsin were used as reference samples. The samples were measured in triplicate. Experiments were carried out at $37^{\circ} \mathrm{C}$. Degradation was also followed by taking photographs of the gels under a UV lamp (Phillips TL-D 18W BLB) at $25{ }^{\circ} \mathrm{C}$. 


\subsection{In vitro cytotoxicity and cytostatic activity}

Before the in vitro assays, PASP-FRFK hydrogel was digested by trypsin. The hydrogels (approximately $150 \mathrm{mg}$ ) were digested using $200 \mu 12.5 \%$ trypsin solution for $4 \mathrm{~h}, 8 \mathrm{~h}, 24 \mathrm{~h}$ at $37^{\circ} \mathrm{C}$ and were shaken every hour. The digestion was stopped by $750 \mu 1$ fetal bovine serum (FBS). As control samples, $2.5 \%$ trypsin solutions were incubated at $37^{\circ} \mathrm{C}$ and were treated with FBS after $4 \mathrm{~h}, 8 \mathrm{~h}, 24 \mathrm{~h}$. The supernatants of the samples were removed, freezed at $-80{ }^{\circ} \mathrm{C}$ until the determination of their in vitro cytotoxicity and cytostatic activity.

The in vitro cytotoxicity of PASP, FRFK and the degradation products of the digested PASPFRFK hydrogel were determined by MTT assay. Adherent HepG2 human hepatoma (ATCC: HB-8065, [50,51]) cells were cultured in RPMI-1640 medium supplemented with $10 \%$ fetal calf serum, $2 \mathrm{mM} \mathrm{L-glutamine,} \mathrm{and} 160 \mu \mathrm{g} / \mathrm{ml}$ gentamicin. Cell cultures were kept at $37{ }^{\circ} \mathrm{C}$ in a humidified atmosphere with $5 \% \mathrm{CO}_{2}$. The cells were grown to confluency and were placed into a 96-well plate with an initial cell number of $5.0 \times 10^{3}$ and initial volume of $100 \mu \mathrm{l}$ per well. After $24 \mathrm{~h}$ incubation at $37^{\circ} \mathrm{C}$, cells were treated with a series of diluted solutions $(100 \mu \mathrm{l}$ each) of PASP, FRFK, or the supernatant of digested PASP-FRFK gel, the final volumes were $200 \mu \mathrm{l}$. Cells were incubated for $16 \mathrm{~h}$. Control cells were treated with serum free medium (RPMI-1640, in the case of PASP and FRFK) or with trypsin-FBS solution (in the case of digestion products) at $37^{\circ} \mathrm{C}$ for $16 \mathrm{~h}$. The cells were washed three times by removing $135 \mu \mathrm{l}$ of the supernatant and replacing it with $135 \mu \mathrm{l}$ serum-free medium. After washing the cells, cell viability was tested using MTT test [52,53]. Briefly, $45 \mu 1$ of MTT solutions were added to each well $(2 \mathrm{mg} / \mathrm{ml}$, dissolved in serum-free medium). After $4 \mathrm{~h}$ of incubation, the plates were centrifuged at $2000 \mathrm{rpm}$ for $5 \mathrm{~min}$, and the supernatant was carefully removed. The precipitated purple crystals were dissolved in $100 \mu \mathrm{DMSO}$, and after agitation for $10 \mathrm{~min}$, the optical density (OD) of the solutions was determined at $\lambda=540 \mathrm{~nm}$ and $620 \mathrm{~nm}$ using an ELISA plate reader (iEMS Reader, Labsystems). Cell viability was calculated with the following equation (Eq. 1):

$$
\text { cell viability }(\%)=\frac{\mathrm{OD}_{\mathrm{s}}}{\mathrm{OD}_{\mathrm{c}}} \times 100
$$

where $O D_{s}$ and $O D_{c}$ are the optical density of treated and control samples, respectively.

The cytostatic activity of the samples was also determined. The cells were cultivated for additional $72 \mathrm{~h}$ after the washing steps with serum-free medium, as written above. Viability was determined by the MTT assay. All cytotoxicity and cytostatic measurements were repeated 
twice on independently obtained cells (two sets of cultured cells); in each individual experiment the number of parallels was three.

\subsection{Drug release measurements}

The release of the FITC-dextran from PASP-FRFK hydrogels was studied in the presence of trypsin (Table 1). A piece of the gel was immersed into $20 \mathrm{ml}$ of PBS containing $2 \mathrm{mg} / \mathrm{ml}$ trypsin. $2 \mathrm{ml}$ samples were withdrawn and replaced with $2 \mathrm{ml}$ fresh medium in every $60 \mathrm{~min}$. The total amount of encapsulated drug was determined after the complete degradation of the gels.

PASP-FRFK in PBS without trypsin and PASP-CA in PBS containing trypsin (Table 1 and Scheme S1) were used as reference samples. As these gels were expected to be stable during the drug release measurement, the total amount of encapsulated FITC-dextran was determined by dissolving these gels after the experiment. $40 \mathrm{mg}$ trypsin was added to the release medium of the reference PASP-FRFK gels and $31 \mathrm{mg}$ solid dithiothreitol was added to the release medium (to reach $10 \mathrm{mM}$ concentration) of the PASP-CA gels to achieve their complete dissolution. The concentration of FITC-dextran in the samples was measured with a fluorimeter (PerkinElmer LS $50 \mathrm{~B}$, USA, $\lambda_{\mathrm{ex}}=490 \mathrm{~nm} ; \lambda_{\mathrm{em}}=515 \mathrm{~nm}$ ). Experiments were carried out at $37^{\circ} \mathrm{C}$. Three parallel samples were measured in each experiment.

\section{Results and discussion}

\subsection{Synthesis of enzyme-degradable hydrogel}

A trypsin-responsive poly(aspartic acid) hydrogel consisting exclusively of amino acids was successfully prepared by cross-linking polysuccinimide with a tetrapeptide followed by the alkaline hydrolysis of the resultant gel. Trypsin belongs to the chymotrypsin superfamily of serine endopeptidases. Human trypsin is formed in the small intestine from its precursor trypsinogen synthesized in the pancreas. The $\mathrm{pH}$ optimum of trypsin is 7.5-8.5. This enzyme hydrolyses the peptide bonds at the C-terminal side of lysine or arginine units. Secondary binding sites on both sides of the scissile bond play only a minor role, although occupancy of these sites does affect the catalytic efficiency of the trypsin [54].

The FRFK tetrapeptide chosen as cross-linker in this study contains a trypsin-specific cleavage site between the second (arginine, R), and the third (phenylalanine, F) amino acid residues. 
FRFK has free amino groups at both ends of the molecule, which can react with succinimide rings in a nucleophilic ring-opening reaction. In our case, these are the $\alpha$-amino group of $\mathrm{N}$-terminal phenylalanine $(\mathrm{F})$ and the $\varepsilon$-amino group of $\mathrm{C}$-terminal lysine $(\mathrm{K})$. The cross-linking of polysuccinimide with the tetrapeptide was carried out in DMSO. As the synthesis of the tetrapeptide resulted in its TFA salt, DBA was used to obtain the free base. After gelation, the gel was immersed into imidazole buffer solution of $\mathrm{pH}=8$ to hydrolyse unreacted succinimide rings into aspartic acid residues. Finally, a stiff, transparent hydrogel formed. The synthesis route of the PASP-FRFK hydrogel is shown in Scheme 1. A representative image about the PASP-FRFK hydrogel is shown in Fig. 1. The gel strength was characterized by the storage modulus of the formed hydrogel. The frequency sweep test showed that the storage modulus of the hydrogel is much higher than the loss modulus in the entire frequency range probed (Fig. 2) and its value was about $3 \mathrm{kPa}$ with negligible frequency dependence indicating the formation of a chemically cross-linked hydrogel. 


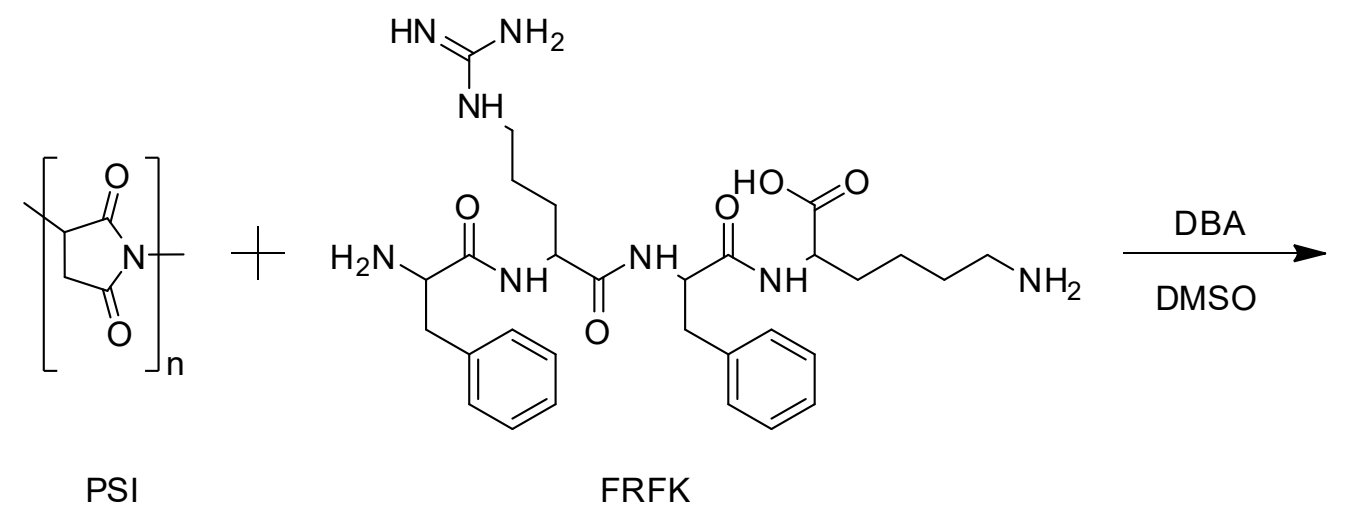

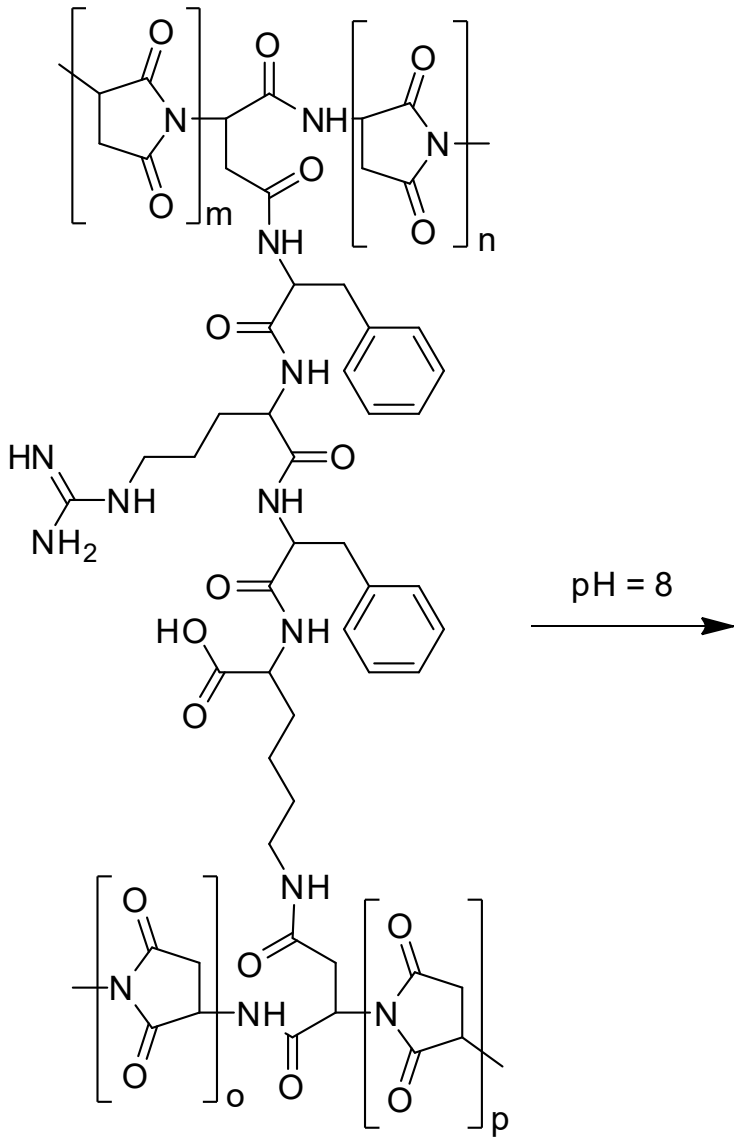

PSI-FRFK
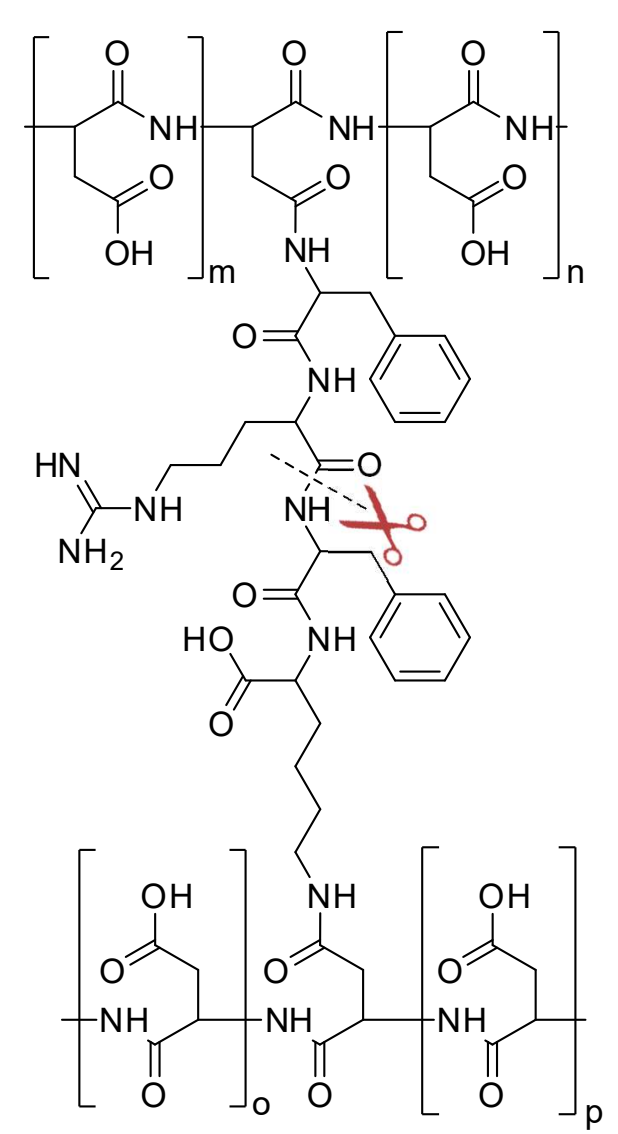

PASP-FRFK

Scheme 1. Synthesis of PASP-FRFK hydrogel: PSI was cross-linked with FRFK tetrapeptide, after that the PSI-FRFK gel was hydrolysed to PASP-FRFK hydrogel in imidazole buffer $(\mathrm{pH}=8)$; the scissors mark the cleavage site of the trypsin 


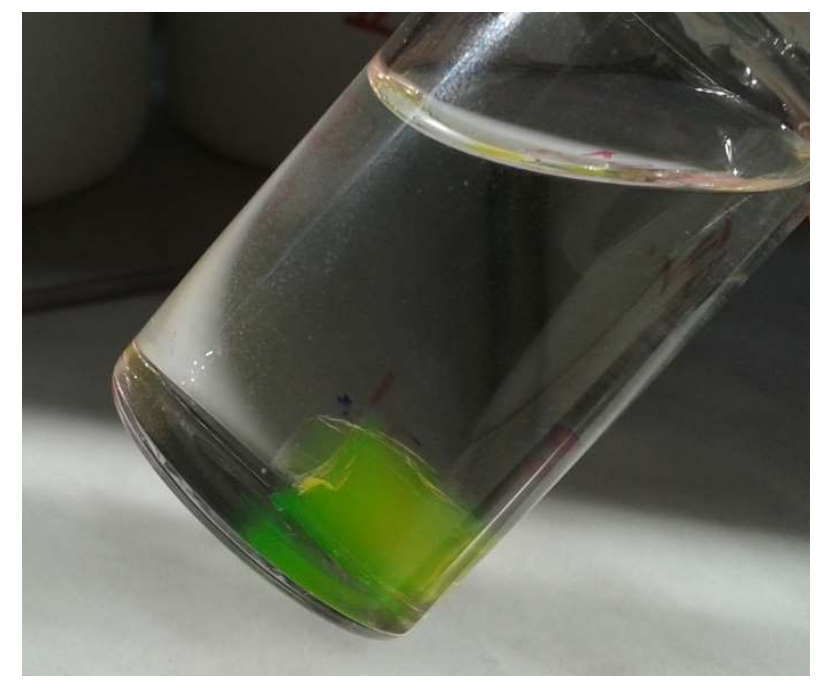

Fig. 1. PASP-FRFK hydrogel loaded with FITC-dextran in PBS

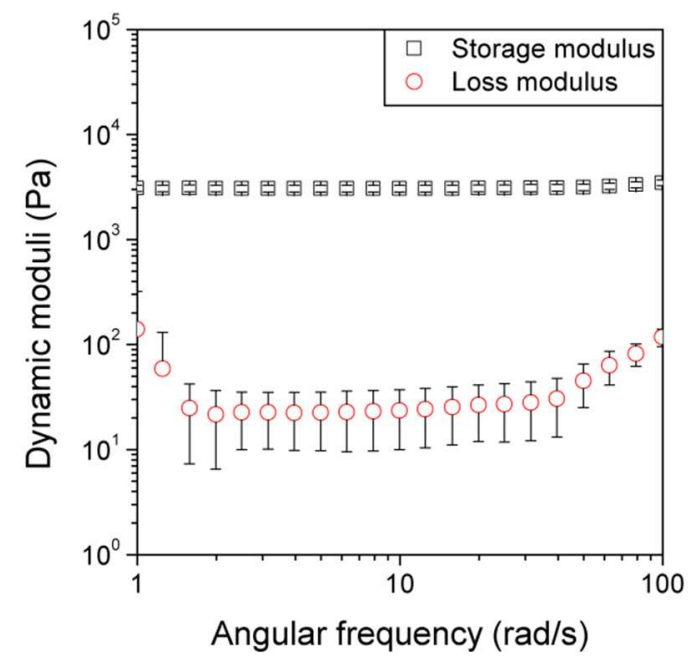

Fig. 2. Storage and loss modulus of the PASP-FRFK hydrogel as a function of angular frequency $\left(\gamma=1 \%, \mathrm{~T}=25^{\circ} \mathrm{C}\right)$.

\subsection{Enzymatic degradation of PASP-FRFK hydrogel}

The cross-linker, FRFK, contains a cleavage site specific to trypsin, thus we expected trypsin-induced enzymatic degradation of the PASP-FRFK hydrogel. A poly(aspartic acid) gel cross-linked with cystamine (PASP-CA) was used in a control experiment as cystamine cannot be cleaved by trypsin (Scheme S1). The PASP-FRFK hydrogel completely dissolved in the 
presence of trypsin within ca. $6 \mathrm{~h}$, as shown by the complete weight loss (Fig. 3a) and disappearance of the gel (Fig. 3b). PASP-CA gel did not degrade under the same conditions (constant mass shown in Fig. 3a and Fig. S3). As these two gels differed only in the type of the cross-linker used, we can conclude that the degradation of the gel took place as a result of the enzymatic cleavage of the trypsin-specific cross-linker, and the polymer backbone remained intact. The enzymatic cleavage is further supported by the stability of PASP-FRFK hydrogel in the absence of trypsin (Fig. 3a).

Surface and bulk erosion are the two main forms of degradation of a polymer hydrogel, however, surface and bulk erosion occur simultaneously for most materials. If surface erosion is prevalent, the polymer degrades from the exterior surface, resulting in size reduction over time, while the hydrogel maintains its bulk integrity. When bulk erosion is dominant, net points break evenly in the entire volume of the material, which leads to increasing degree of swelling in a significant part of the degradation, and the hydrogel splits into small fragments in the final stage of the process. In the first part of our experiment, the mass of PASP-FRFK hydrogel increased slightly (Fig. 3a) which implies bulk erosion, however, the edge of the sample became blurred (Fig. 3b) indicating that surface erosion occurs as well. After the second hour, the mass of the sample decreased at a constant rate (Fig. 3a), indicating that surface erosion became dominant. At the end of the experiment a homogeneous, transparent solution was obtained (Fig. 3b).

The rate of the degradation of such hydrogel in an in vivo environment is influenced by the temperature and the concentration of the trypsin along the small intestine. The collected data is a good starting point for the proposed application, and the rate of the degradation can be tuned later by the degree of cross-linking and the sample size according to the transit time through the small intestine. 
a)
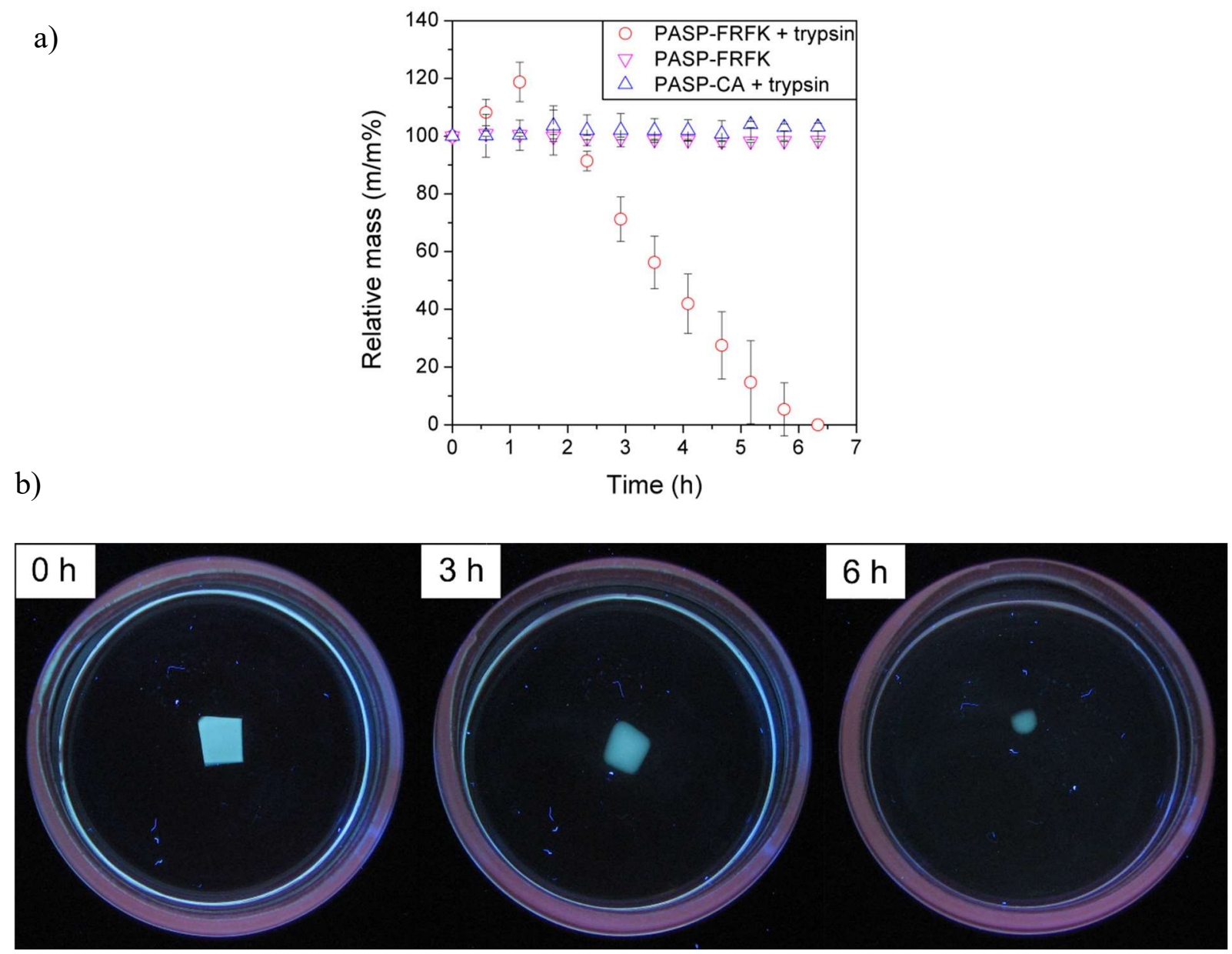

Fig. 3. (a) Changes in the relative mass of hydrogel samples as a function of time: PASP-

FRFK gel in trypsin, PASP- FRFK gel without trypsin and PASP-CA gel in trypsin solution.

(b) Images of the degradation of PASP-FRFK hydrogel in PBS containing $2 \mathrm{mg} / \mathrm{ml}$ trypsin

\subsection{In vitro cytotoxicity and cytostatic activity}

In vitro cytotoxicity and cytostatic (anti-proliferative) activity testing have become important and critical aspects of characterizing the potential of new chemical entities. The in vitro cytotoxic and cytostatic effect of the digested PASP-FRFK, and its building blocks, the FRFK peptide and PASP were determined by a classic colorimetric end point MTT assay. The in vitro cytotoxicity and cytostatic activity of the compounds was measured using HepG2 human hepatoma cell culture.

Tetrazolium type compounds such as MTT, are widely used and accepted for in vitro assessment of metabolic activity of cells; this is one of the most frequently used methods for measuring cytotoxicity and cell proliferation [55]. $\mathrm{IC}_{50}$ represents the concentration of the 
compound which is required for $50 \%$ inhibition. In the case of cytotoxicity, this value determines the concentration which destroys $50 \%$ of the cell population (direct killing), while in the case of cytostatic activity, it shows the concentration which inhibits the cell growth (proliferation) of $50 \%$ of the population. In our study, HepG2 cells have been used to determine in vitro hepatotoxicity because of their ability to sustain some liver-specific functions [56]. The data provide a starting point for further studies.

The cells were treated with the FRFK peptide, PASP and the digested hydrogel solutions. The in vitro cytotoxicity and cytostatic activity of the compounds were characterized by the cell viability as shown in Figs. 4 and 5. Based on the data shown in Fig. 4, the building blocks of the hydrogel, PASP, and the FRFK peptide did not show cytotoxic (Fig 4a) or cytostatic effect (Fig. 4b). Viability was much above $50 \%$ in the covered concentration range on HepG2 cells.

In order to estimate the biocompatibility of the digestion products of the PASP-FRFK hydrogel, digestion by trypsin was aborted at different times, after 4, 8, and $24 \mathrm{~h}$. As the process advanced, the supernatant contained increasing amounts of the digestion products, and finally, no undigested hydrogel was left in the test tubes. The maximum concentration of digestion products on the cells was approximately $1.45 \mathrm{mg} / \mathrm{ml}$ after $24 \mathrm{~h}$ digestion which is comparable to that of the PASP and FRFK solutions in the assays. In this experiment, cell viability is compared to that of the trypsin solutions incubated for the same amount of time. According to the results shown on in Fig. 5, the digestion products of the hydrogel did not show cytotoxicity (Fig. 5a) and cytostatic activity (Fig. 5b) on HepG2 cell culture. Viability was much above $50 \%$.

According to these data, the PASP-FRFK hydrogel is a promising material for biomedical applications as neither its building blocks nor its digestion products show harmful effects on HepG2 cells, although in further studies comprehensive analysis of the interactions between the hydrogel and different human cell lines (derived from blood system etc.) needs to be performed. 

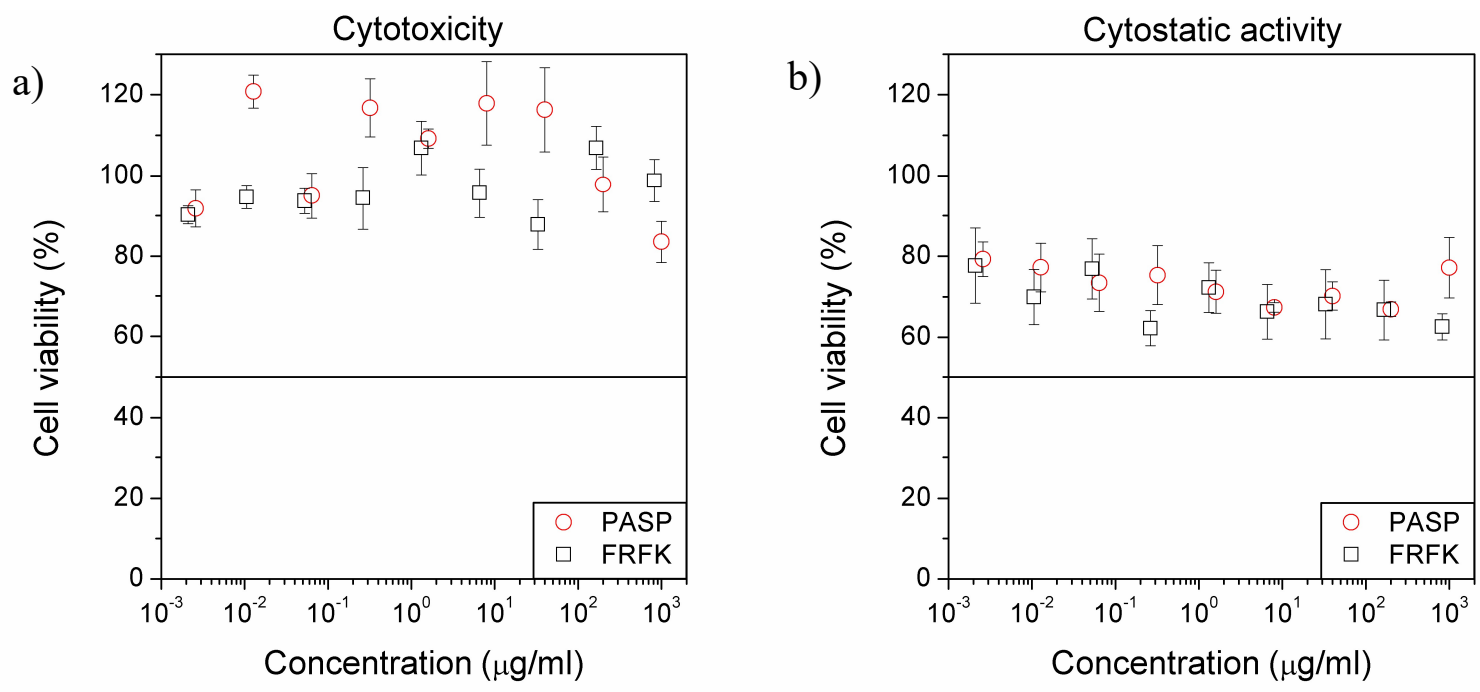

Fig. 4. (a) In vitro cytotoxicity of poly(aspartic acid) and the FRFK peptide and (b) in vitro cytostatic activity of poly(aspartic acid) and the FRFK peptide on HepG2 cell line

a)

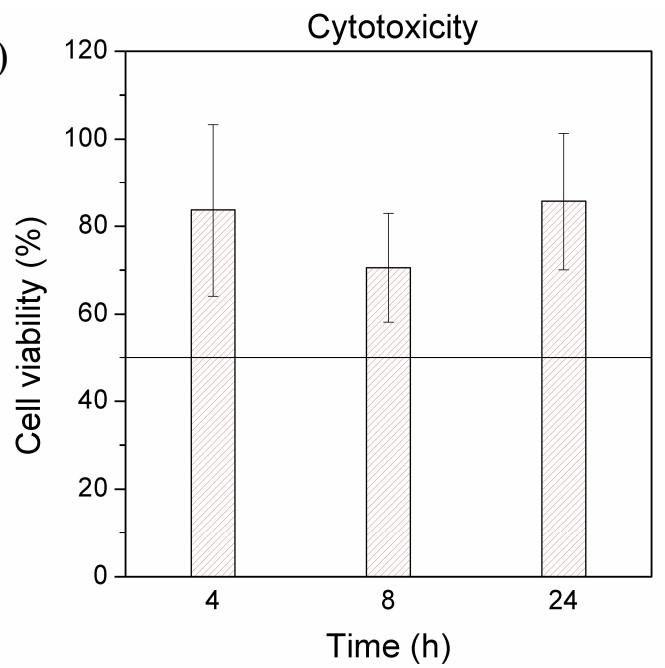

b)

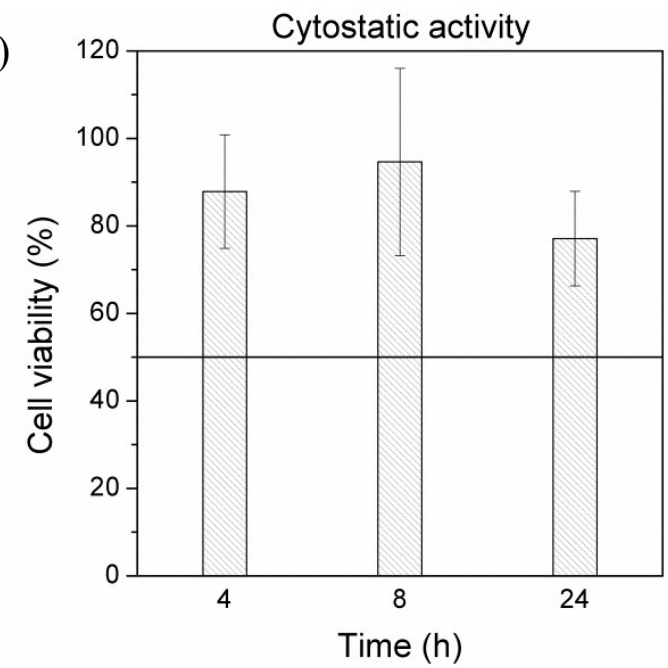

Fig. 5. In vitro (a) cytotoxicity and (b) cytostatic activity of the supernatant of the digested PASP-FRFK hydrogel on HepG2 cell line

\subsection{Release of a macromolecular model drug}

In vitro drug release measurement was carried out since the PASP-FRFK hydrogel was designed for trypsin-induced controlled drug delivery. Fluorescein-isothiocyanate labelled dextran $\left(\mathrm{M}_{\mathrm{w}}=70000 \mathrm{Da}\right)$ was used as model drug, which was encapsulated in the gels during the cross-linking process. 
The PASP-FRFK gel released the model drug as a result of the enzymatic degradation of the gel matrix. After $6 \mathrm{~h}$ the gel dissolved completely and a homogenous solution containing the total amount of the encapsulated model drug was obtained. As shown in Fig. 6, the gel released it in a sustained manner. The drug release followed zero-order kinetic, the kinetic constant was calculated from the slope of the linear curve fitted to the first $6 \mathrm{~h}$ of the measurement and it was found to be $\mathrm{k}=0.1641 / \mathrm{h}$. The reference samples, PASP-FRFK gel in the absence of trypsin and PASP-CA gel in the presence of trypsin remained stable during the $8 \mathrm{~h}$ of the experiment (Scheme S1) and a drug release of only $8 \%$ and $2 \%$, respectively, was measured at the end of the experiment (the kinetic constants are summarized in Table 1). These results prove that the FITC-dextran is entrapped in the PASP-FRFK gel and its release can be triggered by the presence of trypsin.

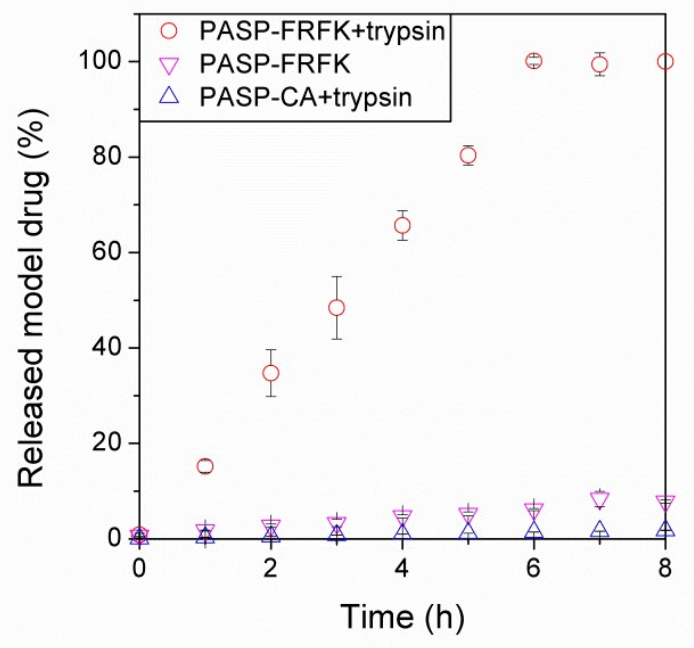

Fig. 6. Release of the macromolecular drug as a function of time: PASP-FRFK gel in trypsin, PASP- FRFK gel without trypsin and PASP-CA gel in trypsin solution

Table 1 Samples of the drug release measurement and the kinetic constants of drug release

Gel Medium Degradation Kinetic constant $(1 / \mathrm{h})$

\begin{tabular}{cccc}
\hline PASP-FRFK & trypsin/PBS & yes & $1.64 \cdot 10^{-1}$ \\
PASP-FRFK $^{1}$ & PBS & no & $9.49 \cdot 10^{-3}$ \\
PASP-CA $^{1}$ & trypsin/PBS & no & $2.17 \cdot 10^{-3}$ \\
\hline
\end{tabular}

\footnotetext{
${ }^{1}$ Reference samples
} 


\section{Conclusion}

A trypsin-degradable polymer gel consisting exclusively of amino acids was prepared in this study. A tetrapeptide was synthesized with a cleavage site specific to trypsin and was used to cross-link polysuccinimide. Poly(aspartic acid) hydrogel was obtained by alkaline hydrolysis. The synthesized hydrogel is degradable in the presence of trypsin and neither the polymer nor the cross-linker is cytotoxic and cytostatic according to in vitro tests on HepG2 cells. The encapsulated macromolecular drug is released from the gel in a sustained manner in the presence of trypsin, while the gel restrained the release of the drug in the absence of the enzyme. In light of the results, the gel can be made suitable for trypsin modulated release of drugs. The synthetic method can be extended to any peptide sequence with a free $\alpha$-amine group at the $N$ terminus and a lysine with free $\varepsilon$-amine group on the $C$-terminus, thus degradable hydrogels can be designed that are specific to any protease enzyme.

\section{Acknowledgements}

This research was supported by the National Research, Development and Innovation Office (NKFIH, FK 125074) and by the Higher Education Excellence Program of the Ministry of Human Capacities in the frame of Biotechnology research area of Budapest University of Technology and Economics (BME FIKP-BIO). B. Gyarmati acknowledges the financial support of the János Bolyai Research Scholarship of the Hungarian Academy of Sciences. A. Szilágyi is grateful for the support of the ÚNKP-17-4-III New National Excellence Program of the Ministry of Human Capacities.

\section{Data availability statement}

The raw/processed data required to reproduce these findings cannot be shared at this time as the data also forms part of an ongoing study. 


\section{References}

[1] D. Buenger, F. Topuz, J. Groll, Hydrogels in sensing applications, Prog. Polym. Sci. 37 (2012) 1678-1719. doi:10.1016/j.progpolymsci.2012.09.001.

[2] N. Annabi, A. Tamayol, J.A. Uquillas, M. Akbari, L.E. Bertassoni, C. Cha, et al., 25th anniversary article: Rational design and applications of hydrogels in regenerative medicine, Adv. Mater. 26 (2014) 85-124. doi:10.1002/adma.201303233.

[3] Y. Qiu, K. Park, Environment-sensitive hydrogels for drug delivery, Adv. Drug Deliv. Rev. 64 (2012) 49-60. doi:10.1016/j.addr.2012.09.024.

[4] E. Krisch, B. Gyarmati, A. Szilágyi, Preparation of pH-responsive poly(aspartic acid) nanogels in inverse emulsion, Period. Polytech. Chem. Eng. 61 (2017) 19-26. doi:10.3311/PPch.9788.

[5] B. Gyarmati, E.Z. Mészár, L. Kiss, M.A. Deli, K. László, A. Szilágyi, Supermacroporous chemically cross-linked poly(aspartic acid) hydrogels, Acta Biomater. 22 (2015) 32-38. doi:10.1016/j.actbio.2015.04.033.

[6] Á. Némethy, K. Solti, L. Kiss, B. Gyarmati, M.A. Deli, E. Csányi, et al., PH- and temperature-responsive poly(aspartic acid)-1-poly(N-isopropylacrylamide) conetwork hydrogel, Eur. Polym. J. 49 (2013) 2392-2403. doi:10.1016/j.eurpolymj.2013.02.015.

[7] B. Gyarmati, Á. Némethy, A. Szilágyi, Reversible response of poly(aspartic acid) hydrogels to external redox and pH stimuli, RSC Adv. 4 (2014) 8764-8771. doi:10.1039/c3ra47530a.

[8] M.C. Koetting, J.T. Peters, S.D. Steichen, N.A. Peppas, Stimulus-responsive hydrogels: Theory, modern advances, and applications, Mater. Sci. Eng. R Reports. 93 (2015) 1-49. doi:10.1016/j.mser.2015.04.001.

[9] M. Zelzer, S.J. Todd, A.R. Hirst, T.O. McDonald, R. V Ulijn, Enzyme responsive materials: design strategies and future developments, Biomater. Sci. 1 (2013) 11-39. doi:10.1039/c2bm00041e.

[10] P.D. Thornton, G. McConnell, R. V Ulijn, Enzyme responsive polymer hydrogel beads, Chem. Commun. (2005) 5913-5915. doi:10.1039/b511005j.

[11] B.P.D. Thornton, R.J. Mart, R. V Ulijn, Enzyme-responsive polymer hydrogel particles for controlled release, Adv. Mater. 19 (2007) 1252-1256. doi:10.1002/adma.200601784.

[12] D. Klinger, E.M. Aschenbrenner, C.K. Weiss, K. Landfester, Enzymatically degradable nanogels by inverse miniemulsion copolymerization of acrylamide with dextran methacrylates as crosslinkers, Polym. Chem. 3 (2012) 204-216. 
doi:10.1039/c1py00415h.

[13] H. Toda, M. Yamamoto, H. Uyama, Y. Tabata, Fabrication of hydrogels with elasticity changed by alkaline phosphatase for stem cell culture, Acta Biomater. 29 (2016) 215227. doi:10.1016/j.actbio.2015.10.036.

[14] M. Kurisawa, E. Chung, Y. Yang, J. Gao, H. Uyama, Injectable biodegradable hydrogels composed of hyaluronic acid-tyramine conjugates for drug delivery and tissue engineering, Chem. Commun. (2005) 4312-4314. doi:10.1039/b506989k.

[15] H. Fuchsbauer, U. Gerber, J. Engelmann, T. Seeger, C. Sinks, T. Hecht, Influence of gelatin matrices cross- linked with transglutaminase on the properties of an enclosed bioactive material using P-galactosidase as model system, Biomaterials. 17 (1996) 1481-1488. doi:10.1016/0142-9612(96)89772-9.

[16] M. Ehrbar, S.C. Rizzi, R.G. Schoenmakers, B.S. Miguel, J.A. Hubbell, F.E. Weber, et al., Biomolecular hydrogels formed and degraded via site-specific enzymatic reactions, Biomacromolecules. 8 (2007) 3000-3007. doi:10.1021/bm070228f.

[17] X. Cheng, J. Liu, L. Wang, R. Wang, Z. Liu, R. Zhuo, An enzyme-mediated in situ hydrogel based on polyaspartamide derivatives for localized drug delivery and 3D scaffolds, RSC Adv. 6 (2016) 101334-101346. doi:10.1039/C6RA18479K.

[18] Q. Xu, C. He, Z. Zhang, K. Ren, X. Chen, Injectable, biomolecule-responsive polypeptide hydrogels for cell encapsulation and facile cell recovery through triggered degradation, ACS Appl. Mater. Interfaces. 8 (2016) 30692-30702. doi:10.1021/acsami.6b08292.

[19] N. Yamamoto, M. Kurisawa, N. Yui, Double-stimuli-responsive degradable hydrogels: interpenetrating polymer networks consisting of gelatin and dextran with different phase separation, Macromol. Rapid Commun. 17 (1996) 313-318. doi:10.1002/marc.1996.030170505.

[20] L. Hovgaard, H. Brondsted, Dextran hydrogels for colon-specific drug delivery, J. Control. Release. 36 (1995) 159-166. doi:10.1016/0168-3659(95)00049-E.

[21] S. Kim, K.E. Healy, Synthesis and characterization of injectable poly(Nisopropylacrylamide-co-acrylic acid) hydrogels with proteolytically degradable crosslinks, Biomacromolecules. 4 (2003) 1214-1223. doi:10.1021/bm0340467.

[22] M.P. Lutolf, J.L. Lauer-Fields, H.G. Schmoekel, A.T. Metters, F.E. Weber, G.B. Fields, et al., Synthetic matrix metalloproteinase-sensitive hydrogels for the conduction of tissue regeneration: Engineering cell-invasion characteristics, Proc. Natl. Acad. Sci. 100 (2003) 5413-5418. doi:10.1073/pnas.0737381100. 
[23] J. Biernaskie, F. Anjum, P.S. Lienemann, M.S. Kallos, M. Ehrbar, Enzyme responsive GAG-based natural-synthetic hybrid hydrogel for tunable growth factor delivery and stem cell differentiation, Biomaterials. 87 (2016) 104-117. doi:10.1016/j.biomaterials.2016.01.050.

[24] A.H. Van Hove, M.G. Beltejar, D.S.W. Benoit, Development and in vitro assessment of enzymatically-responsive poly(ethylene glycol) hydrogels for the delivery of therapeutic peptides, Biomaterials. 35 (2014) 9719-9730. doi:10.1016/j.biomaterials.2014.08.019.

[25] J. Yang, M.T. Jacobsen, H. Pan, J. Kopecek, Synthesis and characterization of enzymatically degradable PEG-based peptide-containing hydrogels, Macromol. Biosci. (2010) 445-454. doi:10.1002/mabi.200900295.

[26] M. Van Dijk, C.F. Van Nostrum, W.E. Hennink, D.T.S. Rijkers, R.M.J. Liskamp, Synthesis and characterization of enzymatically biodegradable PEG and peptide-based hydrogels prepared by click chemistry, Biomacromolecules. 11 (2010) 1608-1614. doi:10.1021/bm1002637.

[27] V. Kumar, J. Kim, S. Son, W. Jong, M.A. Repka, S. Jo, Matrix metalloproteinasesensitive thermogelling polymer for bioresponsive local drug delivery, Acta Biomater. 7 (2011) 1984-1992. doi:10.1016/j.actbio.2011.02.005.

[28] M.F. Maitz, U. Freudenberg, M. V Tsurkan, M. Fischer, T. Beyrich, C. Werner, Bioresponsive polymer hydrogels homeostatically regulate blood coagulation, Nat. Commun. 4 (2013) a.n.: 2168. doi:10.1038/ncomms3168.

[29] S.D. Horava, K.J. Moy, N.A. Peppas, Biodegradable hydrophilic carriers for the oral delivery of hematological factor IX for hemophilia B treatment, Int. J. Pharm. 514 (2016) 220-228. doi:10.1016/j.ijpharm.2016.05.056.

[30] J.M. Knipe, L.E. Strong, N.A. Peppas, Enzyme- and pH-responsive microencapsulated nanogels for oral delivery of siRNA to induce TNF- $\alpha$ knockdown in the intestine, Biomacromolecules. 17 (2016) 788-797. doi:10.1021/acs.biomac.5b01518.

[31] K. Ulbrich, J. Strohalm, J. Kopeček, Polymers containing enzymatically degradable bonds. VI.Hydrophilic gels cleavable by chymotrypsin, Biomaterials. 3 (1982) 150154. doi:10.1016/0142-9612(82)90004-7.

[32] J.L. West, J.A. Hubbell, Polymeric biomaterials with degradation sites for proteases involved in cell migration, Macromolecules. 32 (1999) 241-244. doi:10.1021/ma981296k.

[33] N.S. Khelfallah, G. Decher, P.J. Mésini, Synthesis of a new PHEMA/PEO 
enzymatically biodegradable hydrogel, Macromol. Rapid Commun. 27 (2006) 10041008. doi:10.1002/marc.200600210.

[34] L.C. Glangchai, M. Caldorera-Moore, L. Shi, K. Roy, Nanoimprint lithography based fabrication of shape-specific, enzymatically-triggered smart nanoparticles, J. Control. Release. 125 (2008) 263-272. doi:10.1016/j.jconrel.2007.10.021.

[35] E. Secret, S.J. Kelly, K.E. Crannell, J.S. Andrew, Enzyme-responsive hydrogel microparticles for pulmonary drug delivery, ACS Appl. Mater. Interfaces. 6 (2014) 10313-10321. doi:10.1021/am501754s.

[36] J. Wen, S.M. Anderson, J. Du, M. Yan, J. Wang, M. Shen, et al., Controlled protein delivery based on enzyme-responsive nanocapsules, Adv. Mater. 23 (2011) 4549-4553. doi:10.1002/adma.201101771.

[37] K.N. Plunkett, K.L. Berkowski, J.S. Moore, Chymotrypsin responsive hydrogel: application of a disulfide exchange protocol for the preparation of methacrylamide containing peptides, Biomacromolecules. 6 (2005) 632-637. doi:10.1021/bm049349v.

[38] A.A. Aimetti, A.J. Machen, K.S. Anseth, Poly(ethylene glycol) hydrogels formed by thiol-ene photopolymerization for enzyme-responsive protein delivery, Biomaterials. 30 (2009) 6048-6054. doi:10.1016/j.biomaterials.2009.07.043.

[39] M.P. Lutolf, J.A. Hubbell, Synthesis and physicochemical characterization of endlinked poly(ethylene glycol)-co-peptide hydrogels formed by Michael-type addition, Biomacromolecules. 4 (2003) 713-722. doi:10.1021/bm025744e.

[40] K. Park, W.S.W. Shalaby, H. Park, Biodegradable hydrogels for drug delivery, Technomic Pub, Lancaster, PA, 1993.

[41] A.A. Aimetti, M.W. Tibbitt, K.S. Anseth, Human neutrophil elastase responsive delivery from poly(ethylene glycol) hydrogels, Biomacromolecules. 10 (2009) 14841489. doi:10.1021/bm9000926.

[42] J.M. Knipe, F. Chen, N.A. Peppas, Enzymatic biodegradation of hydrogels for protein delivery targeted to the small intestine, Biomacromolecules. 16 (2015) 962-972. doi:10.1021/bm501871a.

[43] J.P. Schneider, D.J. Pochan, B. Ozbas, K. Rajagopal, L. Pakstis, J. Kretsinger, Responsive hydrogels from the intramolecular folding and self-assembly of a designed peptide, J. Am. Chem. Soc. 124 (2002) 15030-15037. doi:10.1021/ja027993g.

[44] M.C. Giano, D.J. Pochan, J.P. Schneider, Controlled biodegradation of self-assembling $\beta$-hairpin peptide hydrogels by proteolysis with matrix metalloproteinase-13, Biomaterials. 32 (2011) 6471-6477. doi:10.1016/j.biomaterials.2011.05.052. 
[45] C. Németh, B. Gyarmati, T. Abdullin, K. László, A. Szilágyi, Poly(aspartic acid) with adjustable pH-dependent solubility, Acta Biomater. 49 (2017) 486-494. doi:10.1016/j.actbio.2016.11.065.

[46] S.M. Thombre, B.D. Sarwade, Synthesis and biodegradability of polyaspartic acid : A critical review, J. Macromol. Sci. Part A. 42 (2005) 1299-1315. doi:10.1080/10601320500189604.

[47] C. Németh, D. Szabó, B. Gyarmati, A. Gerasimov, M. Varfolomeev, T. Abdullin, et al., Effect of side groups on the properties of cationic polyaspartamides, Eur. Polym. J. 93 (2017) 805-814. doi:10.1016/j.eurpolymj.2017.02.024.

[48] B.Á. Szilágyi, B. Gyarmati, G. Horvát, Á. Laki, M. Budai-Szűcs, E. Csányi, et al., The effect of thiol content on the gelation and mucoadhesion of thiolated poly(aspartic acid), Polym. Int. 66 (2017) 1538-1545. doi:10.1002/pi.5411.

[49] K. Barlos, O. Chatzi, D. Gatos, G. Stavropoulos, 2-Chlorotrityl chloride resin: Studies on anchoring of Fmoc-amino acids and peptide cleavage, Int. J. Pept. Protein Res. 37 (1991) 513-520. doi:10.1111/j.1399-3011.1991.tb00769.x.

[50] B.B. Knowles, C.C. Howe, D.P. Aden, Human hepatocellular carcinoma cell lines secrete the major plasma proteins and hepatitis B surface antigen, Science. 209 (1980) 497-499. doi:10.1126/science.6248960.

[51] D. Simon, D.P. Aden, B.B. Knowles, Chromosomes of human hepatoma cell lines, Int. J. Cancer. 30 (1982) 27-33. doi:10.1002/ijc.2910300106.

[52] Y. Liu, D.A. Peterson, H. Kimura, D. Schubert, Mechanism of cellular 3-(4,5dimethylthiazol-2-yl)-2,5-diphenyltetrazolium bromide (MTT) Reduction, J. Neurochem. 69 (2002) 581-593. doi:10.1046/j.1471-4159.1997.69020581.x.

[53] T. Mosmann, Rapid colorimetric assay for cellular growth and survival: application to proliferation and cytotoxicity assays, J. Immunol. Methods. 65 (1983) 55-63. doi: 10.1016/0022-1759(83)90303-4.

[54] A. Barrett, N. Rawlings, J. Woessner, Handbook of Proteolytic Enzymes, Academic Press, New York, 2013.

[55] F. Denizot, R. Lang, Rapid colorimetric assay for cell growth and survival. Modifications to the tetrazolium dye procedure giving improved sensitivity and reliability, J. Immunol. Methods. 89 (1986) 271-277. doi:10.1016/00221759(86)90368-6.

[56] H.H.J. Gerets, K. Tilmant, B. Gerin, H. Chanteux, B.O. Depelchin, S. Dhalluin, et al., Characterization of primary human hepatocytes, HepG2 cells, and HepaRG cells at the 
mRNA level and CYP activity in response to inducers and their predictivity for the detection of human hepatotoxins, Cell Biol. Toxicol. 28 (2012) 69-87. doi:10.1007/s10565-011-9208-4. 